\title{
Authenticity: Creative Tourism and Large Variation of Community
}

\author{
By Chen-Yi Wu ${ }^{*}$ \\ Chen-Jai Lee \\ Titan Bo-Xiu Jian
}

This article explores the "creative class" of how to produce communities that have different ways of life, cultural diversity, and tolerant attitudes. Creativity provides activities that, when involved in creative tourism, are not limited to a single actor, such as the tourists themselves, but rather are involved in the creative interplay of producers, consumers, policy makers, and landscapes to develop embedded creativity in tourism experiences. This integration has also led some to identify a specific form of creative tourism, which involves the co-creation of participative, 'authentic' experiences. These experiences allow people to develop their creative potential and skills through contact with local people and culture. At the same time, they display many small-scale examples of authenticity in the city, thus pointing to community intimacy, original physical structures, and senses of community belonging. This paper discusses the variation within communities and their processes, as they reflect the cultural and creative fields. The analysis contains an important economic factor, as well as many kinds of work, and the mutual creation of new forms of work and lifestyle in a case study of Zhengxing Street of Tainan City, Taiwan.

Keywords: authenticity, creative class, Creative Tourism

\section{Introduction}

"Creative Class"" is a term proposed by Richard Florida (2002) that refers to a city repurposing its development through the introduction of attractions and innovations to the city, thereby creating competitive advantages of the city. It is composed of scientists and engineers, university professors, poets and architects, and also includes "people in design, education, arts, music and entertainment, whose economic function is to create new ideas, new technology and/or creative content" (Florida, 2002 :8). The Creative Class is not a class of workers among many, but a group believed to bring economic growth to countries that can attract its members. The economic benefits

\footnotetext{
* Ph.D. Candidate, Department of Real Estate \& Built Environment, National Taipei University, Taiwan (R.O.C).

$\$$ Professor, Department of Real Estate \& Built Environment, National Taipei University, Taiwan (R.O.C).

†ssociate Professor, Department of Tourism, Shih Hsin University, Taiwan (R.O.C).

${ }^{1}$ Creative Class is a posited socioeconomic class identified by American economist and social scientist Richard Florida, a professor and head of the Martin Prosperity Institute at the Rotman School of Management at the University of Toronto. According to Florida, the creative class are a key driving force for economic development of post-industrial cities in the United States.
} 
conferred by the Creative Class include outcomes in new ideas, high-tech industry and regional growth. The creative class is also known for its departure from traditional workplace attire and behavior. Members of the creative class may set their own hours and dress codes in the workplace, often reverting to more relaxed, casual attire instead of business suits and ties. Independence is also highly regarded among the creative class and expected in the workplace (Florida 2002). Florida (2004) further suggests that the root of the emergence of the creative class is economic, and is thereby defined as the economic class. $\mathrm{He}$ also mentions that the economic function of the class determines and expresses the choices of the society, culture, and lifestyle made by the members of that class. The creative class relies on creativity to create economic values.

Furthermore, creative tourism is a concept that was only formally defined a decade ago, but in the intervening years it has seen a significant growth worldwide (Richards and Raymond 2000 ;Richards and Wilson 2006). The range of presentations at this conference on different creative tourism programs from all corners of the globe is a clear indication of how widespread it now is. Crispin Raymond and Greg Richards ${ }^{2}$ developed a definition of creative tourism as originally defined creative tourism as: Tourism which offers visitors the opportunity to develop their creative potential through active participation in courses and learning experiences which are characteristic of the holiday destination where they are undertaken (Richards and Raymond, 2000:18). The activities that constitute creative tourism are not actually new; and in fact, people have been engaging in creative activities on holiday for a long time. What is new about creative tourism is the growing scale at which it is happening.

Richards (2011) indicates that the emergence of creative tourism reflects the strategical relationship between tourism and different local markets, including the economic integration with the promotion of creative industry, creative city, and creative class. Creative tourism is becoming more important not just because the tourists are bored, but also because the cultural sector and destination managers are looking for new ways to interact with tourists. It is becoming increasingly important not just to sell the culture of a place, but also to use tourism to support the identity of the destination and to stimulate the consumption of local culture and creativity (Richards and Wilson, 2007). Hence, the quickly developed relationship between tourism and creativity is referred to as a tourism study of creative turn. Creativity generates the content of activities and the tourism atmosphere, where tourism then evolves to further support those creative activities. The increasing integration of tourism and creativity is the apparent tourism remuneration and creative industry. Such

\footnotetext{
${ }^{2}$ Greg Richards is Professor of Placemaking and Events at NHTV Breda University of Applied Sciences and Professor of Leisure Studies at the University of Tilburg in The Netherlands. He has worked on projects for numerous national governments, national tourism organisations and municipalities, and he has extensive experience in tourism research and education, with previous posts at London Metropolitan University (UK), Universitat Roviria I Virgili, Tarragona (Spain) and the University of the West of England (Bristol, UK).
} 
integration results in specific forms that can identify "creative tourism," particularly the participation in common creation. The concept of "authenticity" again transforms the innovative tourism model, where people develop their innovative potential and capacity through the experience of "authenticity" and contact with local people and culture.

Notwithstanding that creative tourism originates from the rebirth of popular culture tourism, it provides an enhanced collaboration between the locality and tourists while also creating more flexibility in experiences of authenticity. Meanwhile, the potential risks of creative speculation and the commercialization of daily life also start to appear (Richards, 2011; Zukin, 2010). People seem to become more enthusiastic about developing innovative potential and consequently, comply with or create experiences through increases in their production or spending capacity. This key concept reveals that creativity is not purported toward oneself only, but also requires characteristics of development, means of economic stripping, and authenticity (Zukin, 2010).

The purpose of the paper is to analyze how the creative class builds a proprietary atmosphere through economy-spurring activities, and thereby creates a creative tourism model. Such models offer more flexibility and authentic living experiences to shape the resulting images. Concurrently, the concept of authenticity is applied to the analysis of how local permanent residents and new immigrants (creative class) engage in reflective creation (innovation) from the habit of a sense of place (space). Is the discussion of authenticity the means of preserving urban elite culture, or can it be used for protecting the right of each resident in terms of life and work? What kind of influence does this process bring to the community?

The framework of the paper is divided into six parts. The section immediately after the introduction includes a review of research regarding the creative class and creative tourism. The foundation of the review is primarily established on the relationship between the development background of creative class and creative tourism. The third section emphasizes research on authenticity, which provides insight to the state and the impact of authenticity, in addition to extending the discussion of current problems or challenges faced by the case. The fourth section regards the scope, method and design of the research. The paper emphasizes a case study of the commercial district on Zhengxing Street in Taiwan City, analyzing the formation of creative class and creative tourism as well as the scope of authenticity. The fifth section is the key to the paper because it analyzes the issues of "who creates the space" through a qualitative research method, including: (1) formation of creative class and creative tourism, and (2) the community soul to authenticity. Finally, the last section presents the conclusion. 


\section{Study Scope and Methodology}

With regards to research scope, the study starts from the Zhengxing Street in Tainan City of Taiwan primarily, extending east to Ximen Road, west to Haian Road, with approximately 60 meters of street (Figure 1). This street was initially unknown to many, but the migration of the creative class (gentries) since 2010 that collaborate and form a virtual street zone reengineering organization, the "Zhengxing Gang,", which not only opens gourmet restaurants and handmade craft shops, but also organizes activities and publishes the "Zhengxing News" magazine. Supported by the "Zhengxing Gang" and community residents, Zhengxing Street is devoted to street zone reengineering and has formed an independent commercial district.

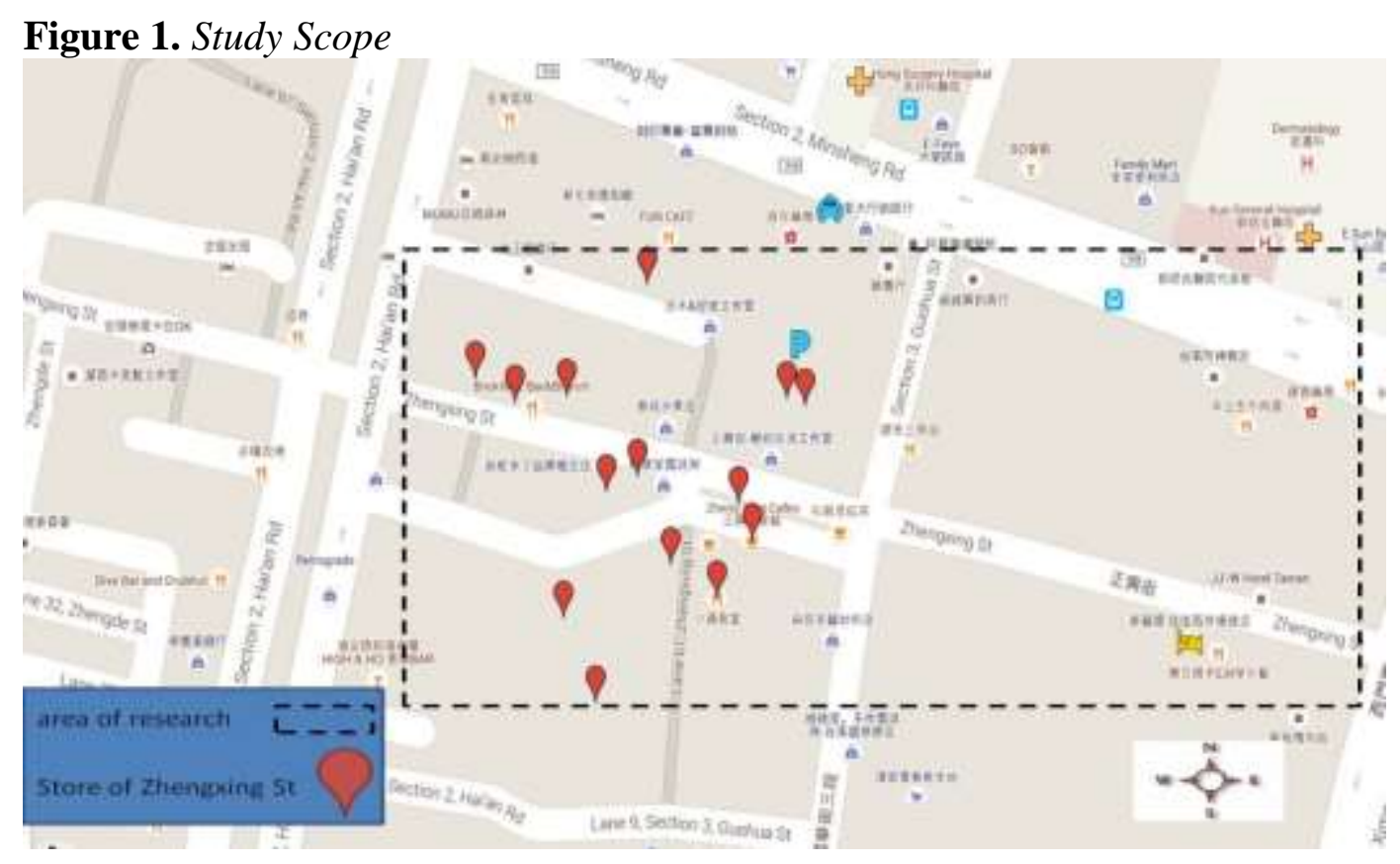

\footnotetext{
${ }^{3}$ The "Zhengxing Gang" is formed by 20 some stores on Zhengxing Street. This name does not refer to the mob but to mutual assistance between the stores. They collectively use power of teamwork to replace mutual competition and they do not need to surrender to the government in order to build the dream street desired by the local owners. For this reason, a legislative organization such as an association is taken into consideration by the local people in order to prevent the limitation on the streets from government policies. The Zhengxing Gang shares the same philosophy with the retaining stores not to turn the street zone into profit-oriented but can create a pleasant place for everyone to visit and the "creation of infinite possibilities of hope for other street zones."

4 Zhengxing Street is the main street for Taiwan tourism, where many tourists gather daily. However excess tourist results in disordered street and many tourists force the way in to visit the stores before they are opened for business, or leave waste voluntarily that cause street mess. Hence the stores often organize activities together in order to maintain the community atmosphere and establish order. Nonetheless the procedures for applying for funds from the government are complex and difficult, so the stores on the street only are able to sponsor each other or raise funds before organizing the activities.
} 
For this reason, Zhengxing Street is representative of the old street and all stores are quite special, preserving the local Taiwanese culture and injecting it with new creative concepts. This concept of creative tourism has built the exceptional space and atmosphere of Zhengxing Street.

With regards to research method, the paper differs from the qualitative model of general in-depth interviews, but adopts methods to implement systematic application and analysis in order to yield theory (Glaser and Strauss, 1967: 1). The reasons for choosing such a method include the following:

First, the study conducts more trail-based qualitative research to study how the proprietary atmosphere can be created through creative tourism models via in-depth analysis. The method further provides more flexible and authentic life experiences to shape its own image. Secondly, an attempt is made to understand the expression and reflection of major issues affecting the local community through authenticity. Although the paper presents identical indepth interviews, the research control and respondents' self-reflection heavily emphasize the control of research outcomes through deliberate research design and logistic thinking. The paper also repeatedly attempts to highlight the issues of research through theme-based conversation, in order to comply with the theoretical paradigms and sensations, which the research intends to discover.

A total of eight relevant people have been interviewed for this paper. Two of them are local community residents; two are students participating in the "Zhengxing News" editing process, and four are from the creative class (please refer to Table 1 Comprehensive Personal Information of Interview Respondents). The time of all interviews fell between 1 hour and 1 hour and 30 minutes for each session. The venue of the interviews was a site convenient for respondents. Interview plans and pre-interview memos were prepared in advance for the interview process. Apart from the transcription of interviews verbatim after their completion, the observation review after each interview is also recorded as part of the research analysis. The arrangement of interview questions was pre-formulated based on the content of relevant literature before conducting the interview. Some questions were asked in response to the answers provided by the respondents regarding previous questions.

The focus of the interviews in this paper mainly surrounded the following topics: How does the creative class build the space of Zhengxing Street? Which elements and conditions affect the shaping of this space? What are the impacts on the community after the creative class enters? Due to the different impacts and mutual relationships of people with different social backgrounds on the community, authenticity is discussed as the process of the creative class integrating creativity. How should the creative class reflect the consumption space and develop new lifestyles, and how can it protect the right of each resident to life and work place? 
Table 1. Comprehensive Personal Information of Interview Respondents

\begin{tabular}{|c|c|c|c|c|}
\hline Interview Respondents & Date of Interview & Interview Duration & $\frac{\underline{\text { Interview }}}{\text { Venue }}$ & Conditions \\
\hline CR01 & March 18, 2016 & 90 minutes & $\begin{array}{l}\text { Living room } \\
\text { of } \\
\text { respondent }\end{array}$ & $\begin{array}{c}\text { Community } \\
\text { residents, } 60 \\
\text { years of } \\
\text { residence } \\
\end{array}$ \\
\hline CR02 & March 12, 2016 & 60 minutes & $\begin{array}{l}\text { In front of } \\
\text { the } \\
\text { respondent's } \\
\text { house }\end{array}$ & $\begin{array}{c}\text { Community } \\
\text { residents, } 81 \\
\text { years of } \\
\text { residence }\end{array}$ \\
\hline S01 & March 18, 2016 & 40 minutes & $\begin{array}{c}\text { On } \\
\text { Zhengxing } \\
\text { Street }\end{array}$ & $\begin{array}{c}\text { Editor of } \\
\text { Zhengxing } \\
\text { News, } 8 \\
\text { months of } \\
\text { participation }\end{array}$ \\
\hline S02 & March 18, 2016 & 30 minutes & $\begin{array}{c}\text { On } \\
\text { Zhengxing } \\
\text { Street }\end{array}$ & $\begin{array}{c}\text { Editor of } \\
\text { Zhengxing } \\
\text { News, } 8 \\
\text { months of } \\
\text { participation }\end{array}$ \\
\hline $\mathrm{CC} 01$ & $\begin{array}{r}\text { October 13, } 2014 \\
\text { March 12, } 2016\end{array}$ & $\begin{array}{l}60 \text { minutes } \\
60 \text { minutes }\end{array}$ & Store & $\begin{array}{l}\text { Clothing } \\
\text { Store } \\
\text { Owner, } 5 \\
\text { years of } \\
\text { operation } \\
\end{array}$ \\
\hline $\mathrm{CC} 02$ & March 12, 2016 & 60 minutes & Store & $\begin{array}{c}\text { Carpentry } \\
\text { Owner, } 3 \\
\text { years of } \\
\text { operation }\end{array}$ \\
\hline $\mathrm{CC} 03$ & March 18, 2016 & 30 minutes & Store & $\begin{array}{l}\text { Restaurant } \\
\text { Owner, } 4 \\
\text { years of } \\
\text { operation }\end{array}$ \\
\hline $\mathrm{CC} 04$ & March 18, 2016 & 30 minutes & Store & $\begin{array}{c}\text { Café and } \\
\text { Tea House } \\
\text { owner, } 5 \\
\text { years of } \\
\text { operation }\end{array}$ \\
\hline
\end{tabular}

Source: Prepared by the Study

\section{The Study of Creative Tourism and Creative Class}

Richards (2011) indicates that the relationship between the quick development of tourism and creativity is known as a tourism research on a creative turn. Creativity has been applied to reengineer traditional cultural tourism, shifting from tangible heritage ${ }^{5}$ to intangible culture, focused to a

\footnotetext{
${ }^{5}$ Heritage tourism is a type of cultural tourism and includes the visiting of cultural heritage, particularly historical building and historical events related relics or royal family, millionaire or celebrity properties. The content of heritage tourism also includes ethnic traditions, art and handcrafts, racial history, social traditions, and cultural festivals. Zeppal and Hall (1991) regard
} 
greater extent on participation and daily-life imagination. Hence, the emergence of creative tourism reflects strategies between tourism and different local markets, including the economic integration of the creative industry, creative city, and creative class. Richards and Raymond (2000) suggest that creative tourism allows tourists to develop self-creative potential from participation in activities, which could become one of the strategies for implementing cultural rebirth. In contrast, Florida (2002) argues that a city itself can access the development of urban repurposing, using "creative class" as the attraction to bring innovation and competitive advantage to the city. In particular, creative class refers to work engagement in "creat[ing] meaningful new forms."

Choices based on creativity spur policy initiatives, including the scope of the economy, culture, and society. Meanwhile, the advantage of claims produced from the network and knowledge that attracts crowds is that they can provoke even more creative activities, thereby producing spillover effects. The public-sector intervention in innovative development involves the following three methods (Campbell, 2011), namely:

\section{- $\quad$ Creative Industries}

The use of creative industry as a strategic objective inspires the development of creative production through support from the "creative industry" sector, including advertising, architecture, art, handcraft, design, fashion, film, music, performing arts, publishing, software, toys and games, television and radio, video games, and tourism industries (DCMS, 1998; Bagwell, 2009; Evans, 2009).

\section{- $\quad$ Creative Cities}

The processes of a creative city advocate for solving the needs of city problems through broader creative methods, which involve creative production development and new governance systems that will thrive in the creativity of the entire society (Landry, 2000). Strategies of a creative city are established on the promotion or manipulation of imagination and creativity, where citizens and creative industries can participate in collective creative activities (Lange et al., 2008; Sepe, 2010).

\section{- Creative Class}

Two types of member compositions exist in the creative class (Florida, 2003). They are:

heritage tourism mostly as nostalgia and the desire to experience the landscape and style of diversified culture. Heritage is also regarded as the most important and fast-growing item in tourism (Herbert, 1995). Hence, heritage requires management and special marketing (Bennett, 1995). 
- $\quad$ Super-Creative Core

It includes a wide range of occupations (e.g. science, engineering, education, computer programming, research), with arts, design, and media workers forming a small subset. Florida considers those belonging to this group to "fully engage in the creative process" (Florida, 2002 :69). The SuperCreative Core is considered innovative, creating commercial products and consumer goods. The primary job function of its members is to be creative and innovative. "Along with problem solving, their work may entail problem finding" (Florida, 2002: 69). This type of member composition is fully committed to creative work. For example, they might design a product for wide manufacturing, marketing, and use by proposing a theory or strategy to be applied in many fields. The core group of the creative class acquires remuneration from regular work, while concurrently solving and responding to current social issues, in addition to discovering problems with responsibilities. These professionals are the classic knowledge-based workers and include those working in healthcare, business and finance, the legal sector, and education.

- Creative Professionals

They "draw on complex bodies of knowledge to solve specific problems" using higher degrees of education to do so (Florida, 2002). This type of class member is widely distributed in knowledge-intense industries, where they exist, integrate and innovate within the conceptual ideologies of talent, inspiration, intelligence, creative thinking, ideas, knowledge, and other humanistic characteristics of knowledge-intense people. For example, they might work in high-tech industries, financial service industries, law, health care industries, and industrial and commercial management fields. Creative experts solve problems with creativity and apply extensive knowledge systems in order to process specific problems, or use complex knowledge in search of innovative solutions.

On one hand, creativity is stylish, not just popular. Creativity is diverse and exists in the form of multiple supplementary enhancements. Creativity requires multiple forms of existence that can implement the development of social and economic environment. Creative cities, creative industries, creative regions, and the competitiveness of personal creativity draw attention from market decision-makers, the media, and the common creative class. On the other hand, creativity provides activity content and tourism with a reciprocal atmosphere so that tourism further supports creative activities. The increasing integration of tourism and creativity are apparent in the creative industry's treatment of tourism. Such integration results in specific forms that identify "creative tourism," which involves participation in common creation.

Hence, creative tourism requires new dimensions as it frequently involves tangible culture and other elements of daily life and local communities. The existing creativity of communities and individuals allows them to commonly create a new scope of space (Cloke, 2007; Richards, 2011). These results could 
be determined by the innovation of implicit knowledge maintained by the producers and consumers, which co-exists in the knowledge and capacity of skill integrated into collaboration, to continue spurring the creative exchanges between tourists and the creative class.

The study will analyze how the creative class builds its own atmosphere through economy-spurring activities, and thereby creates a new creative tourism model. Such a model offers more flexibility and authentic living experiences to shape the image and experience of touristic exchanges. Meanwhile, the potential risks of creative speculation and daily-life commercialization should be avoided, which will be further discussed through the behaviors of authenticity.

\section{Study of Authenticity}

Zukin (2009: 544) explains that authenticity is an ambiguous concept, representing two completely different sources of sensory experience: the foundation from the myth/tradition of time and place and the foundation that includes new history and creative innovation. In other words, authenticity is an issue related to the origin of history and nostalgia in seeking the past. Similar to the understanding of "culture," the definition of authenticity is dynamic. One meaning of authenticity refers to the original or traditional lifestyle, while the other refers to the new culture created by the new generation (Zukin, 2010).

From the perspective of culture, space and urban geography, the monopolization of global urbanization is not only a phenomenon and source of economic crisis, but also connects with the crisis of authenticity. The nonexpected change is seen and perceived through city experience, where major construction projects indicate the control of different spaces and people. The production of independent living by poor people and minorities is eliminated, while the city life may reduce social and aesthetic diversity (Zukin, 2009: 544).

Notwithstanding, authenticity can shape a city space with more progressive advocacies. The most frequently used is gentry and history protectionists, where social preservationists protect group collaboration to prevent displacement and alleviate the tense relationships between groups (Zukin, 2009: 545). Authenticity is a mobile objective that represents the original philosophy of two social groups and the creativity of individuals in modern products. In spite of the fact that it is perceived as a unique habit, authentic subjective impressions can genuinely be applied to aesthetic clues. Meanwhile, authenticity can be used as power leverage that eliminates government from social groups in the city (Zukin, 2010).

The study conducted by Zukin (2010) suggests that, at least in the situation of New York, artists often migrate into declining areas and seek out the path to cheap neighboring space, thereby resulting in gentrification, which finally enhances the space and develops tourism. New immigrants from the Harlem region in U.S. established art galleries, performance venues, restaurants, boutique shops, and hotels through the process of gentrification and inlay creativity. 
This not only offers new consumption space and development of new lifestyles for residents and tourists, but also the opportunity of re-shaping the identity of local communities (Zukin et al., 2009). Hence, authenticity is more than the cultural characteristics left by the past generation and also includes the cultural characteristics created by contemporary generations. The authenticity of the city is formed from the conservation of and tension between origins and new beginnings, which also result in the so-called "urban soul." Cities should provide a fertile land that can brew and create "authenticity" to ensure that disadvantaged groups have the right to live and survive in the city, detaching from the idea of economic development and traditional core values (Zukin, 2010).

Sociologists neglect the necessary structural and systematic factors, as well as excessive symbolic signs, since they are inclined to excessive conceptualization of the different cultural features of difference. In a postindustrial era, the sense of place ${ }^{6}$ expresses regional flow, and the social constructs and market strategies of landscape. The local creators in the resident communities of gentry fashion regions of cities and the rebirth of suburban areas, such as Vermont in the U.S. They create local characteristics and authentic senses of place through social, cultural, and economic influence. The study investigates the reasons that lead to these cultural differences. Is it a hard factor such as the climate and geography? Is it a soft factor, such as culture, which builds cumulative practice and transforms into eternity, or the local authenticity? The study emphasizes modern living development and features by proposing three necessary factors, which creatively differ between different cultures but take consideration of the structural and systematic foundations nonetheless.

1. Individuals must freely make a choice in the place they live, which is most significant.

2. The place must attract outsiders with local history, through any tangible or symbolic landscape of social structure.

3. Local creators must utilize market strategies to emphasize certain elements of the landscape. These elements can be seen as obsolete or incompetent through external factors. Only under these conditions, will

\footnotetext{
"'Sense of place" is a key concept of human geography, which is profoundly affected by phenomenology and Existentialism, with two meanings. One is the place containing highly imaginable characteristics and the other refers to the place with meaning to people, under their awareness. The implication of sense of place is the subjective and emotional attachment from people to the place (Cresswell, 2006). Galliano and Loeffler (1999) suggest that people belong or acquaint with this geographic region through the emotional building of the place before the geographic region (known as space) has meaning for them. The meaning of a place takes place when the space is accompanied by personal special experience, cumulative historic context, and the identity produced. Crang (1998) also mentions that people will produce sense of belonging to this place when acquaint with this place and give meaning to it with gradual production of emotion, thereby perceiving themselves as part of the place. This suggests that people not only define their own position through the sense of place for a place but also define themselves through the place.
} 
the locally born residents and new immigrants engage in the reflective creation of spatial habits (Zukin, 2011).

In summary, cultural power has been derived from the gentrification process through the conceptual discussion of authenticity. Crisis and opportunity for social space transformation could drive permanent residents out of their comfort zone or they could co-exist with permanent residents. The process gradually transforms the previous lifestyles within an area into a place that supports the settlement of different cultural groups, in order to support the dwelling rights of a diversified/pluralistic city.

\section{Reconstructing the Authenticity of Place}

Since regional economic growth is driven by the creator, the creative class owns creative capital. They choose places with diversity, tolerance, and enthusiasm for accepting new ideas. The Creative Class's choice of place to stay considers the factors that are very important. Moreover, "local quality" can be used as one indicator, which refers to a place identified apart from other places as one with exceptional quality and attractiveness. The key to local quality consists of three dimensions, namely:

1. Environment: The integration of the built environment and the natural environment is applicable to pursuing environment of creative life.

2. Figure: The people interact with each other and can enrich the life of the community.

3. Events: Street activities, café culture, art, music and outdoor activities create a lively, stimulating and creative life (Florida, 2004).

\section{Formation of Creative Class and Creative Tourism}

Zhengxing Street organizes activities through Zhengxing Gang, including the Zhengxing Street Parade (Figure 2), the foundation of the "Zhengxing Gang"7 (Figure 3), relevant exhibition activities (Figure 4), and Zhengxing Street activities (Figure 5), where the creative class and creative tourism collide to highlight and create a unique atmosphere and space for the community, thus drawing attention from the city government, media, and tourists.

\footnotetext{
${ }^{7}$ Respondents $\mathrm{CC} 01$ and $\mathrm{CC} 02$ both express that the organization of activities requires funding and they have applied for funding from the district office. However the district office requested them to cooperate with administrative procedures with many conflicts of interests while the funding may not be granted. Hence they intend to raise fund for themselves and that led to the concept of "Zhengxing News." Currently the magazine has published the fourth edition while the time of publishing is non periodic but depends on the mood or situations.
} 


\section{$\underline{\text { Environment }}$}

There is a "West Market (Tainan)" in Zhengxing Street, built during the nine-year Japanese rule under Taizheng (AD 1912), which was the largest market in South Taiwan, selling all kinds of groceries and fresh goods. Tainan people commonly know it as the "big food market". Thus "West Market (Tainan)" has driven Zhengxing Street commercial activity, but now has been in a depression.

"My wife and I have been looking for a suitable place to open a storefront for our brand. We could not find any in Great Taipei area, and we have considered places in Hualian, Yiland and even Shanghai Tianzifan. However all our efforts vanished but under the introduction of friends in Tainan, we built a 45-year old house by accident. We can here in 2012 and there were few stores on this street. We can to renovate and the neighbors looked at us with worries. So what is your business (Taiwanese dialect)" I told them that I was selling clothes. You will be going out of business if you sell clothes. They told me just like, very direct. You will be going out of business. There are not tourists here, only few in a day. Then we really opened the store and it was true, there were some ten people and when we ordered take-out delivery, nobody knew where Zhengxing Stret was... I like the neighbors and the look of this street, such as the grandpa retailer of watermelon, the grandma smoking and drying clothes at the same time, the old fruit store, the rice store no longer in business, the antique fabric market, and sculpturing grandpa,. 'It looks like the poverty town in Steven Chow's movie, mixed and yet harmonious, with a natural silliness and rooting."(2014101013CC01)」

\section{$\underline{\text { People }}$}

"When one gets the impulse and the stores living together will reach high consensus for any activity held (routine annual street trip and everyone travels). Sometimes there are only 3 5 stores thinking about doing something, then more and more people would join. Many people think the atmosphere on our street is interesting... This is the value produced when people connect with each other." (20160312CC01)

"I did not have any idea back then and I always followed the trend. Apart from collecting second hand antiques, I also used to like doing "trendy" things. It was until one predecessor told that, "young man don't forget you are stepping on the land of Taiwan no matter how far you overlook." I realized that I was disoriented and I started thinking seriously the inheritance of traditional craft and treating handmade sofa with serious attitude... It feels like the inconspicuous weeds have transformed from the passion, perseverance and the efforts by a group of people. These people share the work on the street without selfishness. I may look like an idiot but I am able to put down the work and my pride for this group of idiots." (20160312CC02)

"I participate in the street activities but I feel myself detached this year. People participate in the activities of this street voluntarily without feeling any 
pressure. It is like sorting the reclaimed land and some go to help but run away once they discover aching back after some help. Consequently, there was not much help offered... Zhengxing News has only written one column in spite of the length. This time, there is voluntary assistance with the county/city distribution operation that shows some progress. Next time I could help more. I actively participated in the West Market tree protection campaign (tree falling) because it was my childhood memory. It was a pity that some conflicts of interests have been derived from the simple tree and I need to take my stance. Fortunately the tree was resolved for retention eventually. I have been to Zhengxing Street for 5 years. The neighbors are nice and stores are unique. We all back each other up for this street and we do not fight about anything. We only ask for improvement in Tainan." (20160318CC04)

\section{$\underline{\text { Incidents }}$}

"Back then (2013) there was a CD store in Taiwan, which called for an activity for all singers to sing in other people's store. I counter-proposed them and they came to the street while our street became a big space for them. It was the first time when we realize the benefit of collective mobility... I thought that we could search for tourists with the same interests so we all discovered our own strengths. Zhengxing Gang could help with the planning of activities and become more united... WE could drive the community atmosphere and we publish the "Zhengxing News" even if the community does not have any funding. Store managers look after their own stores and it takes no time for us to organize the activities. We will always find someone and we can raise fund when we need money. There are more activities organized, from the music market of "Singing on Zhengxing Street" to the statement made by City Mayor Lai, "Clean up here," the impulsive "Wildness Concert" decided by more than ten men during sweeping the floor, the Useless Festival ${ }^{8}$ for secondhand items bidding, the King of Road Bandit 9, and even the "Office Chair Racing Competition ${ }^{10}$ in April, people from the street are total devoted and they are so very busy." (2014101013CC01,20160312CC01)

\footnotetext{
${ }^{8}$ The first Chinese New Year activity "Useless Festival" was held on January 23 and 24, 2016, funded by Zhengxing News. Different from the optimistic and positive thinking of New Year resolution, the festival encourages the value of life in "two negatives makes one positive" when faced with frustration. The activities include "Failure Music Festival" (sung by singers who have failed in life," "Waste Market (stores selling unused products), and "Failure seminar."

9 To solve illegal parking and temporary parking problems, vehicles having parked are randomly selected with issuance of medal in "King of Road Bandit" and put online through "life show."

${ }^{10}$ The office chair sliding competition was organized in order to revive the attention to the street in Japan. This competition was popular and extended to nationwide with battles taking over 11 cities and for 7 years now. The competition will be introduced overseas starting 2016 and the first stop will be Taiwan. The "Zhengxing Gang" formed by stores on Zhengxing Street in Tainan City with the same appeal will be responsible for the planning and local execution. Mr. Tahara who was organizing the activity in Kyoto also came to Zhengxing Street twice by first contacting and conducting survey, followed by determining the cooperation model with Zhengxing Gang and Tainan City Government. After he returned to Japan, both
} 
The research investigation shows that the creative class has profoundly considered the creation of narratives that connect the stories of community origin and innovative opening. Respondents repurpose community development and bring innovation to the community through the pursuit of living quality and lifestyle, thereby acquiring competitive advantage for community attraction. Most importantly, they engage in works that "create meaningful new forms." The activities of new forms provide local residents and tourists with opportunities to participate. The activities require face-to-face settlement and co-development of creative tourism for self-creative potential, as well as granting greater extent of participation and the imagination of daily life.

It is worthwhile to note that the respondents accept the various frustrations and difficulties of the participation process, which thereby blends with innovation and original possibilities to shape an irreplaceable atmosphere. Meanwhile, such integration results in specific forms of identifying "creative tourism," which involves the participation and experience of life from a mode of common creation.

Figure 2. Zhengxing Street Trip

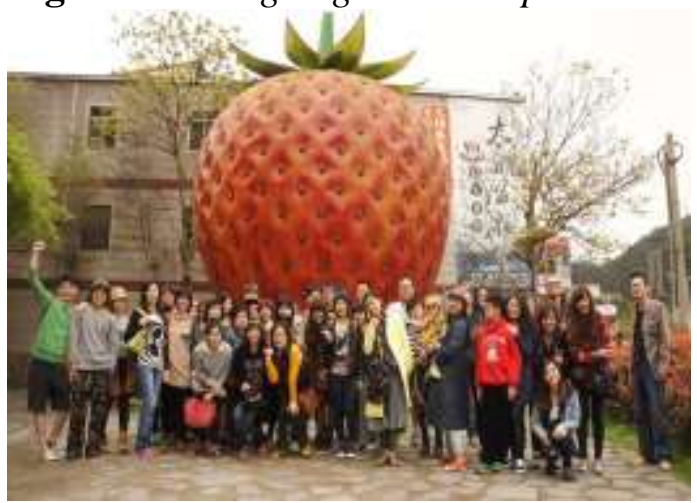

Photo Courtesy by: Rainbow is Coming FB

Figure 3. Zhengxing News NO.4

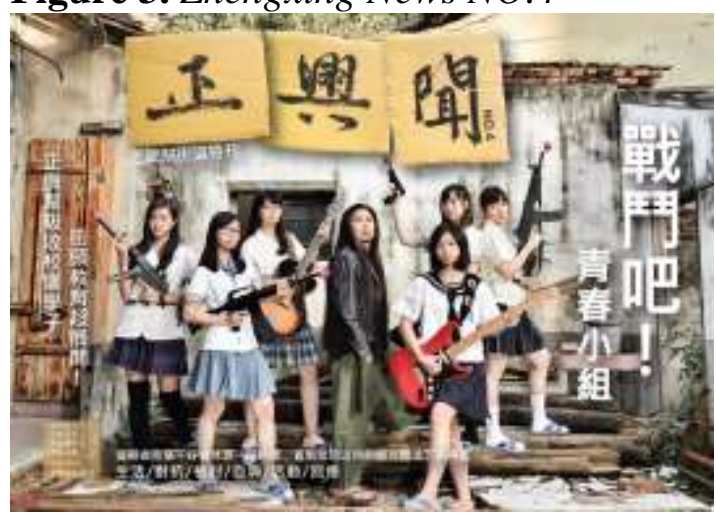

Photo Courtesy by: Taken by researcher

parties discussed details via Facebook Group. This private-sector cross-border fun competition was held on April 24, 2016. 
Figure 4. Exhibition Activity - Tainan Alley/Lane Collection Market (10 alley/ land treasure hunting and four major street-side stages)

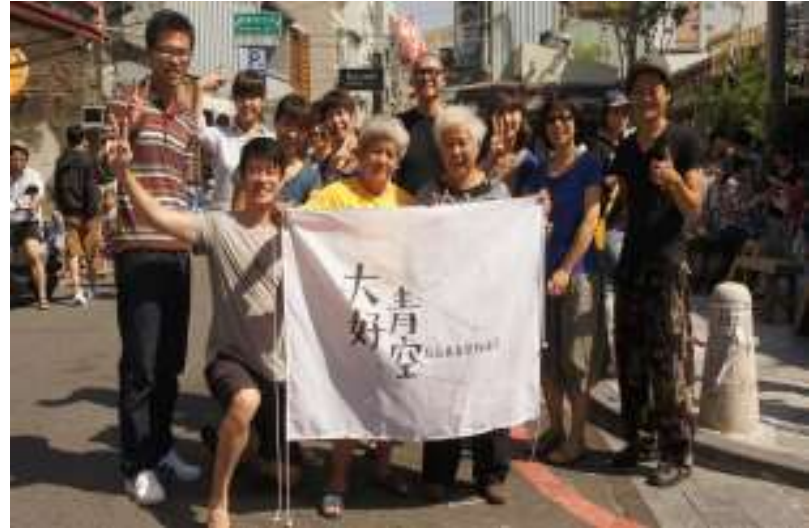

Photo courtesy by: Rainbow is Coming FB

Figure 5. Zhengxing Street Performance

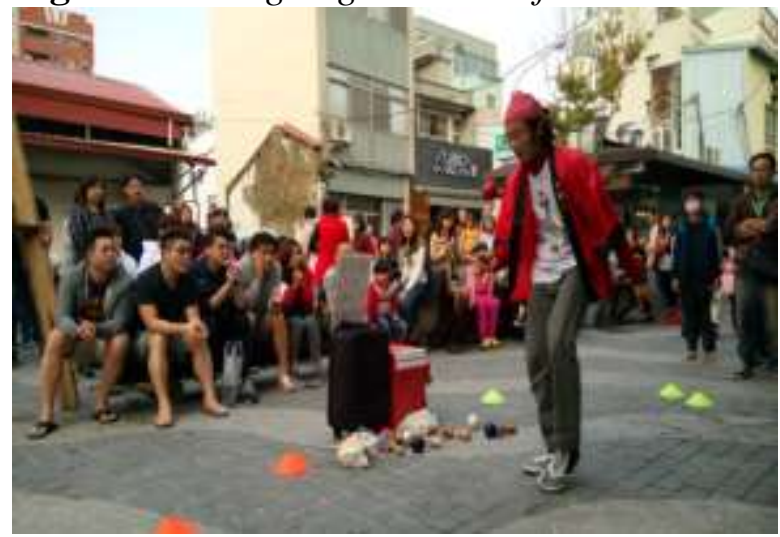

Photo courtesy by: Taken by researcher

\section{Soul of Authentic Community}

The soul of authentic community is the foundation from the myth/tradition of time and place, as well as the foundation that includes new history and creative innovation. In other words, authenticity is an issue related to both the origin of history and the nostalgia in seeking the past. The following will examine the elements of authenticity, including lifestyle, social interaction, diversity, and tolerance (Florida, 2004; Zukin, 2010).

\section{$\underline{\text { Lifestyle }}$}

When choosing a place to live, the consideration of lifestyle usually accounts for more than just employment. Some people suggest that if they did not need to pay a major price for any fun thing they did, they would refuse to work or no longer look for a job. These fun things include concerts, art exhibitions, technology exhibitions, outdoor activities, and fairs. Some people also describe themselves or their friends as only moving to a place based on a consideration of lifestyle. They later started working due to financial problems. 
Some people only move to a place for its lifestyle and only search for work after moving. Their highest expectation for one place is to participate in activities or sites. This place could be a city with credibility of "worth living," and that also signifies the cultural atmosphere of creative time in this place, or the adaptability to the place.

"This lane is hidden with many stories and going through this lane is like walking in a maze. There is one story to every spot and makes one want to shop again and again. You will find different life philosophy anywhere you go... We added new elements to the old house where nobody lived before while preserving the traditional and original philosophies." (20160312CC02)

"In one day's routine, I would get up in the morning to accompany my children for half hour before going out for food shopping. One hour later I would prepare the ingredients when I arrive to the store. Life is some simple and fund, as everyone talks to each other." (20160318CC03)

"The government does not know what we really want." Most stores do not wish Zhengxing Street to only develop into a commercial district filled with money but expect it to become a community. Everyone interacts purely with each other in the community and look forward to customers with the right taste and higher class. They do not welcome tourists who parking illegitimately and litter." (20160312CC01, 20160318CC03)

"I didn't think too much. My friends are here and I like to walk in the environment here. I returned to Tainan when I left northern Taiwan and I rented an old house here... I hoped a special restaurant that combines the atmosphere of Japanese restaurant and Taiwanese restaurant. We only offer 2 sets of meals and the menu will change following the season change. I don't even know what will be available. Sometimes I would develop new menu or specific hidden meal for the street activities, such as the 424 limited "Enriched Lunch Box." (20160318CC03)

The respondents express that they value lifestyle more than work conditions. Lifestyle includes attitude towards work, and they blend work content into their notions of lifestyle. This persistence relies on innovative factors and is unconstrained by tradition. They thus integrate work with life to create new objects and activities.

\section{Social Interaction}

People always discover some social activities in their communities. However, people live nearly anonymously in a society with high levels of mobility. Therefore, whether a community can promote social interactions between people or not becomes increasingly important. Ray Oldenburg (1991) used the term third place ${ }^{11}$, is a space that does not belong to family and workplace, but provides a place for people to interact with familiar people or other people. The appearance of this space aims to search for people of

\footnotetext{
11 Oldenburg calls one's "first place" the home and those that one lives with. The "second place" is the workplace - where people may actually spend most of their time. Third place, then, is "anchors" of community life and facilitate and foster broader, more creative interaction.
} 
common interests who can talk pleasantly. Therefore, this space becomes the "heart of a community's social vitality" (Oldenburg, 1991) and determines if the community has problems in the key function of attraction. The significance of the third space stems from the receptiveness of the work itself. Due to differences in a daily life routine and work time, actual contact between people becomes increasingly difficult and can only be provided with limited formality via the Internet or another information system. In response to this, the third space provides the possibility of direct contact with people. For example, walking along the street to the store to chat can be a new and important part of life.

"Mutual-air lifestyle is formed naturally on the street. For example, the son of the grandma across the street passed away and now she lives alone, I would bring her noodles which she like. Sometimes tourists park scooters in front of the grandmother's house, and I would help her move the scooter. We interact frequently and naturally. We live on the street and not just open the stores here." (20160312CC01)

"This attitude or not just doing business helps Zhengxing Street to maintain its own style when the crowd gathers more on Zhengxing Street. For example there are many tourists today and some would park illegally or litter, I would scold them and put the note written with "You parked your scooter randomly and I got back injured from moving your scooter" on the scooter." (20160312CC02)

"We use the animated cat (Zhengxing cat) and other stores have their own design. The cat I designed helped me win the champing, for reason I don't even know why. They said the cat won the first place and I was thrilled and didn't expect to win the first place by changing some clothes. I sang a karaoke song that day when we were to complete the building. They reported this car and the ZhengXing New reported on me. I was planning to catch that guy writing article about me and how he could write about me without my permission. I will catch that guy soon (laughter). Everyone wants to take a photo with the cat and saw that. They think it is funny and the grandmother is funny. Why do they say that I could speak Japanese? I am trying to catch that guy and if I get him, I will bring them to you. I will pinch his ears and everyone (community) laughs about me. I will tell them that I will soon catch that guy." (20160318CR01)

"Some will sponsor or provides support." For example, they will provide cupboard for writing in case they want to hold activities. At first we support them with photos or filming when they have activities, then they came for the fourth publication." (20160318S01)

"Someone parked in front of my door and I asked for help from the village head. My son could not move his bicycle home. Many tourists come to this place in the recent 1 2 years and the community starts developing develop. The tourists park illegally and litter also. We hope that we all show respect to each other and please lease the space of door for us to access with convenience. We do not have opinion about it and you can also park on the other side of our door."(20160312 CR02) 
In summary, the community life of Zhengxing Street provides opportunities for people from different social backgrounds to interact socially, because the difference and mixture of the creative class, local residents, and tourists takes place in this space. It is an open, heterogeneous space without assimilation. The respondents expect to have their own lifestyle and need the power of "social interaction" to understand and interact with each other better through time. For this reason, social interaction develops into social tolerance and cohesion, which reduces social compulsion and isolation, thereby adjusting the unbalanced community and promoting the natural interaction of social fusion. Respondents suggest that they should not be homogenously integrated, because it will ultimately fail. On the contrary, we should open and encourage the possible fusion with them.

\section{Diversity and Tolerance}

Diversity means "stimulation" and "vitality." People are usually attracted to places with an open mind and diversity. A community with diversity is the benchmark of open mindedness. Persons with creativity are more willing to accept the impact of different dimensions. They like to meet and interact with people of different backgrounds and personalities, exchanging their viewpoints and discussing problems. Diversity can encourage the locality to see potential for the fusion of culture and ideas, which are tolerant to strangers while also contributing to innovation, adventure, and new business.

"Zhengxing Street starts holiday pedestrian walk" and "advocates for the intent of street closure as the solution to safety concern of people and car joint traffic. The street zone must first create comfortable environment before attracting the business opportunities." (20160312CC01)

"This street has undergone major changes. We all manage this community together and it is fun. Today is a busy day (Kind of Road Bandit). People park their scooters randomly and now we need to catch the owners. The game is designed to inform people that scooters should not be tossed around or they will catch you. But it is still a fun game." (20160318CR01)

\footnotetext{
${ }^{12}$ The increasing number of tourist results in long line for fruit, shaved ice and pedestrians on the holidays. The traffic of vehicles and temporary parking could bring trouble to the street zone while relatively increasing the danger for pedestrians to shop on the streets. In view of this, the street stores and residents find it difficult to solve the problems through oral persuasion and hence the Zhegnxing Gang discussed and integrated street opinions to reach consensus. With the collaboration from city government and the resources of city government integrated by the Department of Economic Development, street is closed on the weekend since October 3, 2015 (Saturday). The area on Zhengxing Streets (Haian Road to Guahua Street Section), between $1 \mathrm{pm}$ to $6 \mathrm{pm}$ on Saturdays and Sundays are closed as pedestrian zone and all vehicles are prohibited from entering. This is a safe pedestrian street environment. Another special feature of street closure is the installation of road carrier on the pedestrian, which was also completed by stores on the street. The "Rainbow Is Here" steered the planning. Zhengxing Street friendly illustrator Jia-Hui Lu (Beat Life Illustration) takes the sample of each store manager to draw into the shape of cat. The "Xiaoman Restaurant" and the "Xiyi Design Store" assist with contacting manufacturers to collaborate and complete the 25 Zhengxing Cat cutouts for use as instruction and information announcement during the period of street closure.
} 
"We move around and only rely on our relationship. We interact with friendship. This is like a friendship built from revolution. First you do it and everyone else watches before giving you a hand and the method of change. We have only accomplished a minor part. For example, some of the grandmothers are land owners and some have the power. Their houses can be sold up to NTD60 million. They might have wanted to sell the house but when they interact with you, they discover that they really want to live here and do not wish to sell the house. In some way, this curbs the possibility of growth in housing price because the deal could be scary. This way the house previously selling for NTD8 million would be bid to NTD40 million and finally dealt. Then everything would be ruined here." Zhengxing Music Instrument was opened on the street for 3 years but closed due to the excessively high renewal rent proposed by the landlord."

"Different voices would appear and we all hold them together. There are many people opposing to the development of the community but we do not know how to really define it or who could correct define anywhere. We just want to observe and reflect. The most common discussion on Zhengxing Street compared with other region is the people to people exchange and that the humanistic value surpasses the value of the store. However there are also many disadvantages and inadequacies, as well as things that merit scolding. Nonetheless these things could not deny the positive values produced from our interaction and connection with other people in the past few years." (20160312CC01)

"Some people would want to work on land speculation or take free ride. For example, the Zhengxing Music Instrument that has been opened 3 years on the street but the contract was expired this March. The landlord proposed excessively high renewal rent but the store could not afford and then left. We would still do something about it when faced with them." (20160312CC02)

"The landlord now raises the rent without caring about if you make money or not. Young people here are working hard for the community so sometimes this part is difficult to comment." (20160318CR01)

"The difficulty should be the time coming here and everything was too abrupt." Their activities are all very sudden and temporary. For example, they mentioned to us that the fourth edition would be published about this April back at the end of last year, but the suddenly tell us that the fourth edition is about to be published one day, maybe before the Chinese New Year. As for the next edition, the fifth edition could appear when you suddenly wake up. They like to have college students helping, as if injecting new vitality." (20160318S01 、S02)

These examples show that the respondents have different voices toward the development of Zhengxing Street and will not accept compulsion or exclusion due to the difference in personal views or ideology. On the contrary, this place creates a space infused with various cultures and ideas. In spite of this, the community faces tourist disturbances; the creative class faces high rent under the prosperity of Zheng Xing Street; but despite these many abrupt activities, all residents maintain a respectful and tolerant attitude. They face 
everything developed on Zhengxing Street and know that they should not take the gift for granted, so they still uphold the reflective, innovative, adventurous, and striving mentality in order to continue exchanging their viewpoints and discussing their problems. Zhengxing Street reflects what Zukin (2010) has mentioned: creativity should not be self-oriented, but should require the development of characteristics and means of economic stripping in order to implement authenticity and avoid the potential risk of creativity speculation and daily life commercialization.

\section{Conclusion}

The paper applies qualitative research to analyze the spurring of economic activities used by the creative class through innovation, in addition to building a proprietary atmosphere, thereby steering a community towards the creation of an innovative tourism model. Consequently, tourists and local residents are provided with more flexible and authentic living experiences. They choose Zhengxing Street for its diversity, tolerance, and willingness to accept new ideas. Particularly, "local quality" is a considerable indicator that gives exceptional quality and attraction to this place. In terms of environment, the creative class combines the built environment of the old houses with the natural environment in a way that is suitable for pursuing a total environment of innovative living. In terms of people, the respondents interact and exchange various ideas to enrich the life of this community. In terms of events, the case displays diversity, uniqueness, and fun activities that help to create lively, stimulating, and creative life. The respondents interact with each other via these activities to promote community cohesion and an intangible mutual understanding. Meanwhile, such a model will also naturally generate creative tourism as this space provides worthwhile experiences and exchanges.

The theme and conversations with respondents contribute to the discussion of authenticity in these cases. The reflexive creation (innovation) by local residents and the creative class engaged in managing sense of place (space) mainly consists of lifestyle, social interaction, diversity, and tolerance. Findings show that they are not constrained by tradition in terms of lifestyle, but rather integrate their work with life to create new objects and activities. In terms of social interaction, the respondents expect to have their own lifestyle, and hence need the power of "social interaction" so that they can acquaint themselves with each other more and interact more effectively as time passes. For this reason, social interaction develops into social tolerance and cohesion, which reduces social compulsion and isolation, thus adjusting the unbalanced community and promoting the natural interaction of social fusion. With regards to diversity and tolerance, the respondents utilize different voices regarding the development of Zhengxing Street and will not show compulsion or exclusion due to difference in personal views or ideology. On the contrary, this place creates a space infused with various cultures and ideas. 
Finally, the concept of authenticity has taken a much more ambiguous form following the renegotiation of the place's lease and its re-orientation as a 'multicultural' place. Identities may now play off elements of the area's past and present itself in ways respectful to the community's authenticity. Thus, social and cultural networks of new producers and consumers create, nurture, and often capitalize on a completely new sense of place.

\section{References}

Bennett M (1995) Heritage marketing: The role of information technology. Journal of Vacation Marketing 3: 272-280.

Bagwell S (2009) Creative clusters and city growth. Creative Industries Journal 1: $31-46$.

Crang M (1998) Cultural geography. London: Routledge.

Cresswell T (2006) On the move: mobility in the modern Western world. New York: Routledge.

Campbell P (2011) You say 'creative', and I say 'creative'. Journal of Policy Research in Tourism, Leisure and Events 3: 18-30.

Cloke P (2007). Creativity and tourism in rural environments. In: Richards G and Wilson J (eds.), Tourism, creativity and development. London: Routledge, 37-47.

DCMS (1998) Creative industries mapping document. London: Department for Culture, Media and Sport.

Evans G (2009). Creative cities, creative spaces and urban policy. Urban Studies 46: $1003-1040$.

Florida R (2002) The rise of the creative class: And how it's transforming work, leisure, community and everyday life. New York: Basic Books.

Florida R (2004) The rise of the creative class. New York: Basic books.

Florida R (2003) Cities and the Creative Class. City \& Community 2(1): 3-19.

Galliano SJ and Loeffler GM (1999) Place assessment: How people define ecosystems. Oregon: U.S. Department of Agriculture.

Glaser B and Strauss A (1967) The discovery of grounded theory. Chicago: Aldine.

Herbert DT (1995) Heritage places, leisure and tourism. In: Herbert DT. (eds.) Heritage, Tourism and Society. New York: Mansell, 1-20.

Landry C (2000) The creative city: A toolkit for urban innovators. London: Earthscan.

Lange B, Kalandides A, Stober B, and Mieg HA (2008) Berlin's creative industries: Governing creativity?. Industry and Innovation 15: 531-548.

Oldenburg R (1991) The Great Good Place. New York: Marlowe \& Company.

Richards G (2011) Creativity and tourism: The state of the art. Annals of tourism research 38(4): 1225-1253.

Richards G and Wilson J (2007) Tourism, Creativity and Development. London: Routledge.

Richards G and Wilson J (2006) Developing Creativity in Tourist Experiences: A Solution to the Serial Reproduction of Culture?. Tourism Management 27: 12091223.

Richards R and Raymond C (2000) Creative tourism. ATLAS News 23: 16-20.

Sepe M (2010) Urban policies, place identity and creative regeneration: the Arabianranta case study. 14th International Planning History Conference, Istanbul, 12-15 July 2010. 
Zeppal H and Hall C (1991) Selling art and History: Cultural heritage and tourism. Tourism Studies 2: 47-55.

Zukin S (2009) Changing landscapes of power: Opulence and the urge for authenticity. Urban and Regional Research 33(2): 543-553.

Zukin S et al. (2009) New retail capital and neighborhood change: boutiques and gentrification in New York City. City and Community 8(1): 47-64.

Zukin S (2010) Naked city: The death and life of authentic urban places. Oxford: Oxford University Press.

Zukin S (2011) Reconstructing the authenticity of place. Theory and Society 40(2): 161-165. 